\title{
Spectroscopic and Theoretical Study of the Grafting Modes of Phosphonic Acids on ZnO Nanorods
}

\author{
Emanuele Smecca, Alessandro Motta, Maria Elena Fragalà, Yana Aleeva, \\ and Guglielmo Guido Condorelli*
}

Department of Chemistry, Università degli Studi di Catania and INSTM UdR di Catania, v.le A. Doria 6, 95125 Catania, Italy

\section{Supporting Information}

\begin{abstract}
Metal oxides are versatile substrates for the design of a wide range of SAM-based organic-inorganic materials among which $\mathrm{ZnO}$ nanostructures modified with phosphonic SAM are promising semiconducting systems for applications in technological fields such as biosensing, photonics, and field-effect transistors (FET). Despite previous studies reported on various successful grafting approaches, issues regarding preferred anchoring modes of phosphonic acids and the role of a second reactive group (i.e., a carboxylic group) are still a matter of controversial interpretations. This

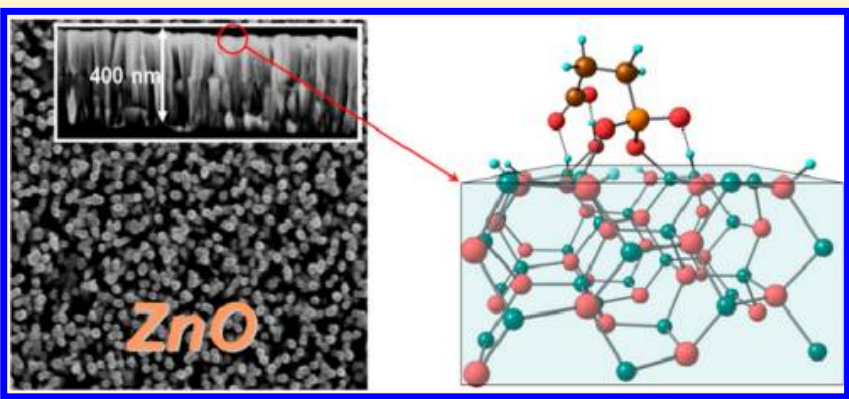
paper reports on an experimental and theoretical study on the functionalization of $\mathrm{ZnO}$ nanorods with monofunctional alkylphosphonic and bifunctional carboxyalkylphosphonic acids. X-ray photoelectron and infrared spectroscopies have been combined with DFT modeling to explain and understand the interactions that drive the surface anchoring of phosphonic acids on $\mathrm{ZnO}$ surface. It was found that both monofunctional and bifunctional acids anchor on $\mathrm{ZnO}$ through a multidentate bonding which involves both $\mathrm{P}=\mathrm{O}$ and $\mathrm{P}-\mathrm{O}$ moieties of the phosphonic group. Moreover, anchored bifunctional acids bend to the surface, promoting a further interaction between surface hydroxyl groups and carboxylic terminations. This secondary interaction can be limited by increasing the surface density of the anchored molecules.
\end{abstract}

\section{INTRODUCTION}

Functionalization of metal oxides with self-assembled monolayers (SAMs) is nowadays a field of great interest since it is a powerful and low-cost method to form stable and flexible surfaces with controlled properties. ${ }^{1-3}$ Possible applications range from protective coatings which enhance mechanical properties (such as adhesion, friction, and corrosion resistance $)^{4-6}$ to functional layers in specific electronics devices such as field-effect transistors, ${ }^{7,8}$ sensors, ${ }^{9-12}$ or dye-sensitized solar cells (DSSCs). ${ }^{13}$ Therefore, the present decade has seen a surge of interest in the modification of metal oxides $\left(\mathrm{TiO}_{2}, \mathrm{AgO}\right.$, $\mathrm{Al}_{2} \mathrm{O}_{3}, \mathrm{ZrO}, \mathrm{ZnO}$, ITO) with SAM having various anchoring groups, among which phosphonic moieties were proven to be an efficient alternative to the more often adopted carboxylic and siloxane tethering functionalities. ${ }^{14-17}$ Among mentioned metal oxides, nanostructured $\mathrm{ZnO}$, a wide-band-gap semiconductor $\left(E_{\mathrm{g}}=3.37 \mathrm{eV} \text { at room temperature }\right)^{18}$ used in sensors, ${ }^{19}$ electronic devices, ${ }^{20,21}$ and solar cells, ${ }^{22-24}$ is a promising substrate for the design of SAM-based organicinorganic materials of technological relevance. ${ }^{25-32}$ Examples of SAM-functionalized $\mathrm{ZnO}$ nanostructures include nanorods modified either with carboxyalkylphosphonic acids (HOOC$\left.\left(\mathrm{CH}_{2}\right)_{n} \mathrm{P}(\mathrm{O})(\mathrm{OH})_{2}(n=2,9)\right)$ for biosensing ${ }^{25}$ or with $\mathrm{C} 60$ functionalized phosphonic linkers for photonic devices ${ }^{26}$ and nanowire-based $\mathrm{ZnO}$ field-effect transistors (FET) which use long-chain alkylphosphonic acids as gate dielectrics. ${ }^{27}$
Despite various studies reported on a wide range of successful anchoring approaches, issues regarding preferred anchoring modes (monodentate, bidentate, tridendate, bridging bidentate, etc.) of phosphonic acids on $\mathrm{ZnO}$ and the role of a second reactive group (i.e., a carboxylic group) are still a matter of controversial interpretations. ${ }^{25,16}$ Since a powerful support for the understanding of the interactions between adsorbates and oxide surfaces is given by DFT modeling, ${ }^{33,34}$ this paper reports on a combined experimental and DFT study on the functionalization process of rodlike $\mathrm{ZnO}$ structures with alkylphosphonic, carboxyalkylphosphonic, and, for comparison, carboxylic acids to elucidate the anchoring modes of phosphonic and carboxylic groups and their interplay when both functionalities are present in the molecule. In particular, the monofunctional tetradecylphosphonic (TDPA), propylphosphonic (PPA), and 16-bromohexadecanoic (BrHDA) acids and the bifunctional 16-phosphonohexadecanoic (CPHDA) and 3-phosphonopropanoic (CPPA) acids (Figure 1) were used to functionalize $\mathrm{ZnO}$ nanorods (NRs) grown as nanocolumnar films (Figure 2 left). In addition, rodlike powders with hexagonal cross section (Figure 2 right) have been similarly functionalized. Characterization of modified $\mathrm{ZnO}$ surfaces was performed with X-ray photoelectron spectroscopy

Received: September 10, 2012

Revised: January 24, 2013

Published: February 27, 2013 


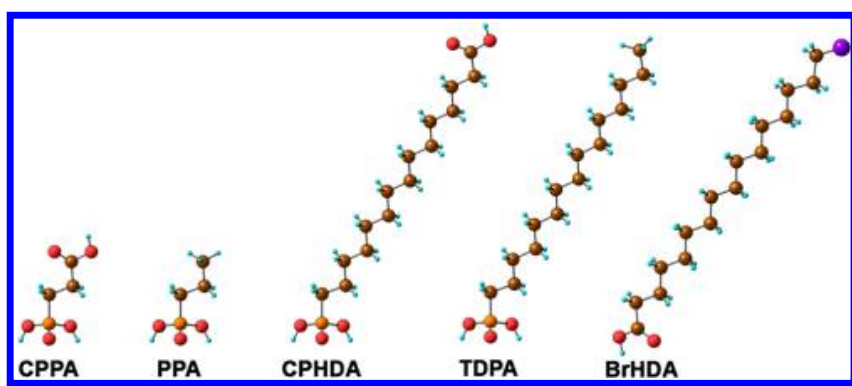

Figure 1. Molecular structure of adopted phosphonic and carboxylic acids. $\mathrm{O}$ atoms in red, $\mathrm{P}$ in orange, $\mathrm{C}$ in brown, $\mathrm{H}$ in light blue, and $\mathrm{Br}$ in violet.

(XPS) for both powders and films. To obtain vibrational information on anchored molecules, FT-IR spectroscopy of functionalized rodlike powders has been performed. Anchoring modes of phosphonic acids on $\mathrm{ZnO}$ surfaces were modeled by DFT, and obtained results in terms of calculated stable configurations and simulated IR spectra were compared to experimental data.

\section{EXPERIMENTAL SECTION}

Reagents. CPHDA (97\%), PPA (95\%), CPPA (94\%), and BrHDA (99\%) were purchased from Sigma-Aldrich and TDPA (99\%) from Alfa Aesar. All solvents were purchased from Sigma-Aldrich. All solvents and chemical products were used without further purification.

Substrate Preparation. ZnO NRs (Figure 2 left) were grown on $\mathrm{Si}(100)$ substrates by combining metal-organic chemical vapor deposition (MOCVD) and chemical bath deposition (CBD) according to the literature. ${ }^{35}$ Rodlike powders (Figure 2 right) were also obtained from the $\mathrm{CBD}$ solution. Briefly, a CBD nutrient bath was prepared by mixing equimolar aqueous solutions of $\mathrm{Zn}\left(\mathrm{CH}_{3} \mathrm{COO}\right)_{2} \cdot 2 \mathrm{H}_{2} \mathrm{O}(0.05$ M) and $N, N, N^{\prime}, N^{\prime}$-tetramethylethylenediamine (TMEDA). Growth temperature was fixed at $70{ }^{\circ} \mathrm{C}$. $\mathrm{CBD} \mathrm{ZnO}$ formation occurs either by homogeneous nucleation in solution or by heteronucleation on a seeded substrate. The former nucleation process produces $\mathrm{ZnO}$ rodlike powders while the latter nanocolumnar films. The XRD patterns of $\mathrm{ZnO}$ samples indicate that both films and powders possess the wurtzite structure (Supporting Information Figure S1).

Surface Functionalization. $\mathrm{ZnO}$ NR films were functionalized by immersion in a phosphonic acid solution $(1 \mathrm{mM})$ in THF (or ethanol) for $2 \mathrm{~h}$. Before functionalization all samples were cleaned by sonication in 2-isopropanol $(10 \mathrm{~min})$ and, then, in dichloromethane ( $10 \mathrm{~min}$ ), followed by drying with $\mathrm{N}_{2}$. After the grafting process, samples were sonicated in THF (or ethanol) for $10 \mathrm{~min}$ to eliminate physisorbed species and dried with $\mathrm{N}_{2}$.

Rodlike powders were functionalized by dispersion $(0.05 \mathrm{~g})$ in a phosphonic acid solution $(1 \mathrm{mM}$, unless otherwise specified) in THF (or ethanol). The dispersion was stirred for 2 $\mathrm{h}$, and then powders were collected by centrifugation at 6000 rpm for $10 \mathrm{~min}$. After the grafting, powders were cleaned by redispersion in THF (or ethanol) and recollection by centrifugation (three cycles).

Surface Characterization. XPS spectra were run with a PHI 5600 multitechnique ESCA-Auger spectrometer equipped with a monochromated $\mathrm{Al} \mathrm{K} \alpha \mathrm{X}$-ray source. Analyses were carried out at a $45^{\circ}$ photoelectron angle (relative to the sample surface) with an acceptance angle of $\pm 7^{\circ}$. The XPS binding energy (BE) scale was calibrated by centering $C 1$ s peak due to hydrocarbon moieties and "adventitious" carbon at 285.0 eV. 36,37

Transmission FTIR measurements were recorded on a JASCO FTIR 430, using the $\mathrm{KBr}$ pellet technique, with 100 scans collected per spectrum (scan range 560-4000 $\mathrm{cm}^{-1}$, resolution $4 \mathrm{~cm}^{-1}$ ). SEM micrographs were obtained using a LEO SUPRA 55VP equipped with a field emission gun.

Computational Details. DFT-based simulations were performed with the CP2K/Quickstep package, using a hybrid Gaussian and plane wave method. ${ }^{38}$ The Goedecker-TeterHutter pseudopotentials ${ }^{39}$ together with a 400 Ry plane wave cutoff were used to expand the densities obtained with the Perdew-Burke-Ernzerhof (PBE $)^{40}$ exchange-correlation density functional. A double quality DZV Gaussian basis set was employed for the $\mathrm{Zn}$ atom, and a triple quality TZVP Gaussian basis set was employed for all the other atoms. Dispersion forces are taken into account with the Grimme DFT-D3 method. $^{41}$ Molecular geometry optimization of stationary points used the Broyden-Fletcher-Goldfarb-Shanno (BFGS) method. Vibrational analysis was carried out to obtain IR information within the harmonic approximation approach. Only the gamma point was considered in a supercell approach. CP2K calculations, since are based on a mixed plane-wave and atom-basis centered approach, are not significantly affected by the BSSE (that is correlated only to the atom centered basis set approximation), so it was not taken into account. In particular, it was demonstrated ${ }^{42}$ that with the same theoretical approximation (PBE, basis set $=\mathrm{MOLOPT}^{43}$ and $\mathrm{GTH}$ pseudopotential) BSSE represents a very little contribution to

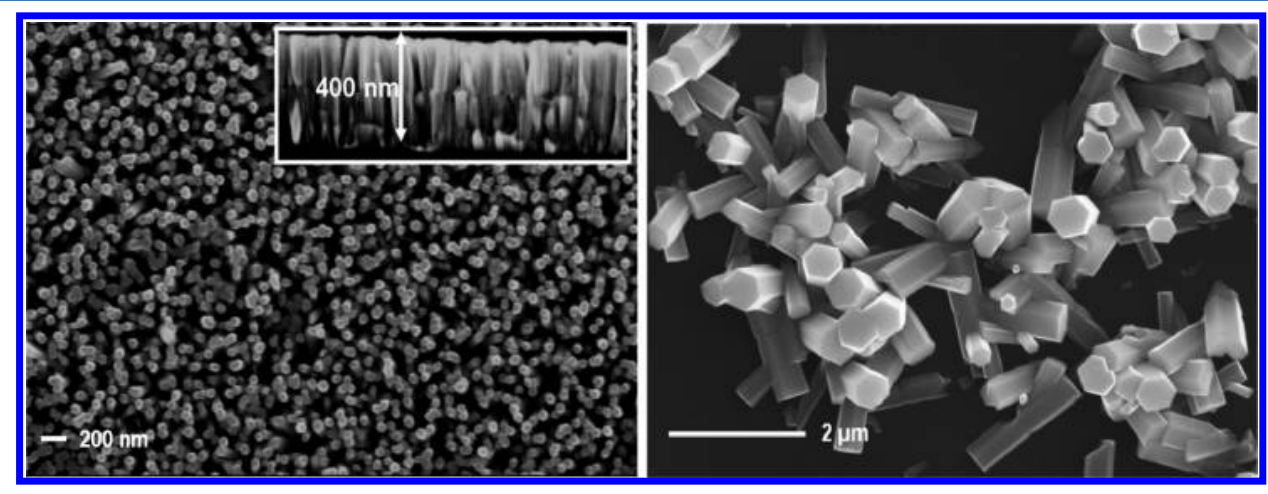

Figure 2. NR films (left) and rodlike powders (right). 
the total interaction energy spanning into the $2.0-2.5 \mathrm{kcal} / \mathrm{mol}$ range.

Wurtzite crystals are dominated by four low Miller index surfaces (Figure 3): ${ }^{44}$ the nonpolar (10-10) and (11-20) surfaces and the polar (0001) formed by zinc-terminated (0001) and oxygen-terminated (000-1) islands. ${ }^{45}$

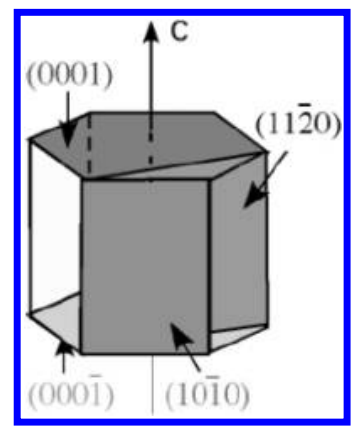

Figure 3. Scheme of the most relevant surfaces of $\mathrm{ZnO}$ crystals.

In this contest, the $\mathrm{ZnO}$ surfaces (0001)-Zn, (10-10), and (11-20) were constructed for the adsorption process using a slab model having a $(2 \times 2)$ surface unit cell (see Supporting Information for details). Only one adsorbate molecule was placed on one side of the slab to reduce lateral interactions.

For the comparison between mono and double condensation of the CPPA molecule on the $\mathrm{ZnO}$ surface, entropic and solvent contributions were computed by Gaussian09 code $^{46}$ using a simplified molecular model. In this case, calculations were performed at the level of the B3LYP formalism using the standard all-electron $6-31 \mathrm{G}^{* *}$ basis for all the atoms. ${ }^{47}$ Entropic contributions were evaluated by a frequency analysis performed at $298 \mathrm{~K}$. Solvent effects were modeled using the polarized continuum (overlapping spheres) formalism (PCM) of Tomasi and co-workers. ${ }^{48}$

For all the other calculations only the electronic energy was computed considering the entropic and solvation effects comparable for all the systems.

\section{RESULTS AND DISCUSSION}

XPS Characterization. The grafting process of phosphonic acids on $\mathrm{ZnO}$ nanorods was monitored by XPS. Table 1 compares elemental compositions obtained from XPS analyses of $\mathrm{ZnO} \mathrm{NRs}$ before and after functionalization with PPA, CPPA, TDPA, and CPHDA from ethanolic or THF solutions.

For all functionalized samples, the presence of $\mathrm{P} 2 \mathrm{p}$ peak is a reliable indication of the phosphonic acid grafting on the

Table 1. XPS Atomic Composition of (a) As-Grown $\mathrm{ZnO}$ NRs and NRs Functionalized with (b) PPA, (c) CPPA, (d) TDPA, and (e) CHDPA $^{a}$

$\begin{array}{lcccc} & \mathrm{C} & \mathrm{O} & \mathrm{Zn} & \mathrm{P} \\ \text { (a) } \mathrm{ZnO} & 15.8 & 50.7 & 33.6 & \\ \text { (b) } \mathrm{PPA} & 17.6 & 49.2 & 29.4 & 3.7 \\ \text { (c) } \mathrm{CPPA}^{b} & 21.0 & 49.0 & 25.2 & 4.7 \\ \text { (d) } \mathrm{TDPA}^{b} & 44.9 & 34.9 & 18.3 & 1.8 \\ \text { (e) } \mathrm{CPHDA} & 50.3 & 30.0 & 16.9 & 2.8\end{array}$

${ }^{a}$ No significant differences have been found adopting either ethanol or THF as solvent for film functionalization. ${ }^{b} \mathrm{CPPA}$ functionalization of NRs was performed only in ethanol solution due to the poor solubility of CPPA in THF. surface (Table 1). Moreover, the position of this band gives information on the nature of the interaction between the phosphonic molecule and the surface. In order to have reliable references to evaluate binding energy (BE) shifts, P 2p XPS regions of phosphonic acids (PPA, TDPA, CPHDA, and CPPA) as pure powders have been preliminarily recorded (Figure $4 \mathrm{f}$ and Figure $\mathrm{S} 2 \mathrm{f}-\mathrm{i}$ in the Supporting Information).

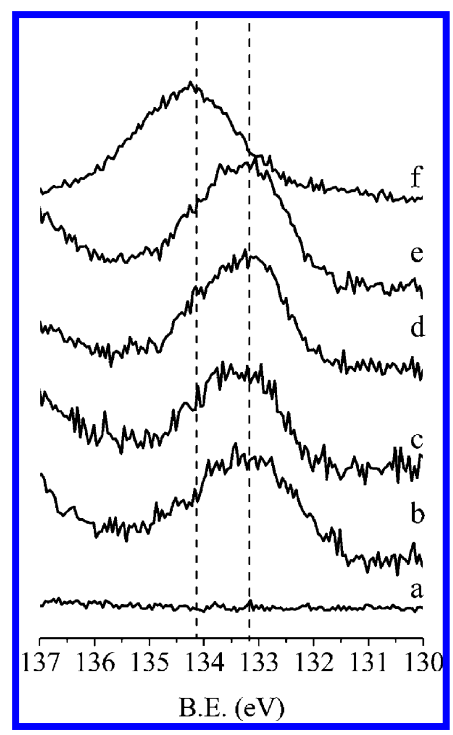

Figure 4. XPS spectra of $\mathrm{P} 2 \mathrm{p}$ region of (a) ZnO NRs, (b) CPHDANRs, (c) TDPA-NRs, (d) CPPA-NRs, and (e) PPA-NRs. Spectrum $f$ of pure PPA powders is added as reference. $P 2 p$ spectral regions of pure TDPA, CPPA, and CPHDA powders (Figure S2f-i) are shown in the Supporting Information.

The $\mathrm{P} 2 \mathrm{p}$ peak of all phosphonic acids consists of an unresolved doublet centered at $134.1 \mathrm{eV}$ as expected for not deprotonated $-\mathrm{PO}_{3} \mathrm{H}_{2}$ acid. ${ }^{49-51}$ By contrast, after grafting on $\mathrm{ZnO}$ nanostructures, the $\mathrm{P} 2 \mathrm{p}$ band (Figure $4 \mathrm{~b}-\mathrm{e}$ ) is shifted at $133.2 \mathrm{eV}$. This shift toward lower $\mathrm{BE}(0.9 \mathrm{eV})$ compared to free acids is associated with the deprotonation of $-\mathrm{POH}$ terminations, as it is generally accepted that $\mathrm{P} 2 \mathrm{p}$ BE value of $\left[\mathrm{PO}_{n}(\mathrm{OH})_{m}\right]^{x-}$ groups depends on the number of $\mathrm{O}$ bonded to $\mathrm{P}$ and on the $n / m$ ratio. ${ }^{52,53} \mathrm{~A}$ shift of about $0.5 \mathrm{eV}$ has been associated, in previous papers, ${ }^{54}$ with the deprotonation of one $\mathrm{P}-\mathrm{OH}$ termination since the $n / m$ ratio increases from $1 / 2$ in $\mathrm{PO}(\mathrm{OH})_{2}$ to 2 in $\left[\mathrm{PO}_{2} \mathrm{OH}\right]^{-}$. The greater shift observed in this work can be associated with the deprotonation of both $-\mathrm{POH}$ terminations ${ }^{54}$ with the occurrence of two $\mathrm{P}-\mathrm{O}-\mathrm{Zn}$ bonds. Note that similar shifts (around $0.8 \mathrm{eV}$ ) have also been reported for the grafting of phosphonic acids on transition metal oxide surfaces. ${ }^{49}$

Figure 5a-c shows XPS $C 1$ s region of bare NRs and of PPA and TDPA functionalized NRs (PPA-NRs and TDPA-NRs). The C 1s peak of bare NRs is a convolution of two components. The first component $\left(\mathrm{C}^{0}\right)$ is centered at 285.0 $\mathrm{eV}$, and it is due to the ubiquitous "adventitious" carbon. A second component $\left(\mathrm{C}^{4+}\right)$ at $289.0 \mathrm{eV}$ is associated with carbonate species. $\mathrm{C} 1 \mathrm{~s}$ regions of PPA-NRs and TDPA-NRs show only the band $\left(\mathrm{C}^{0}\right)$ centered at $285.0 \mathrm{eV}$ due to aliphatic carbon of grafted molecules and to "adventitious" carbon, while carbonate related band at $289.0 \mathrm{eV}$ is no longer detectable. The absence of this peak indicates that carbonate contaminants present on the surface of as-deposited films are efficiently removed by the grafting process of phosphonic acids. 


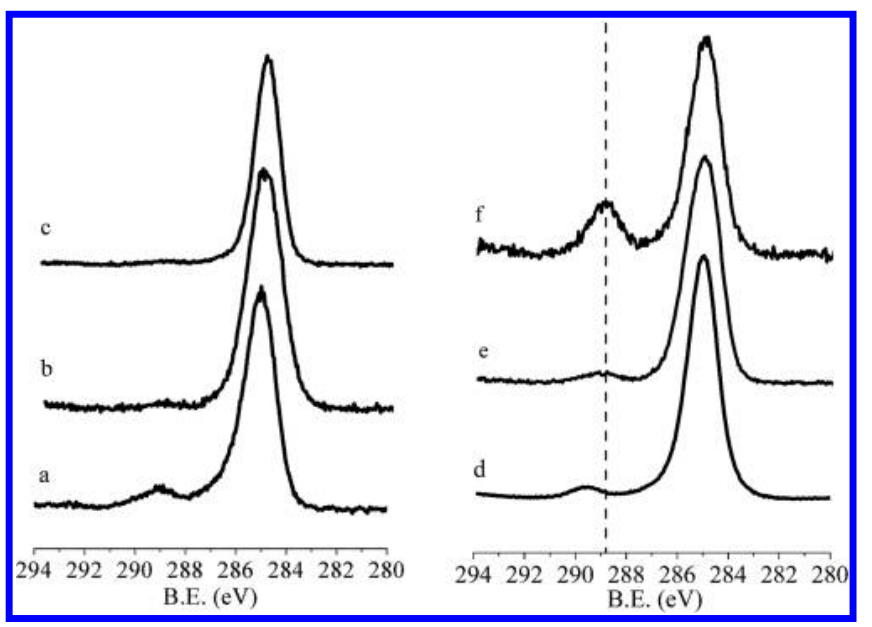

Figure 5. XPS spectra of $\mathrm{C} 1 \mathrm{~s}$ regions of (a) ZnO NRs, (b) PPA-NRs, (c) TDPA-NRs, (d) pure CPHDA powders, (e) CPHDA-NRs, and (f) CPPA-NRs.

In Figure 5d-f, $\mathrm{C}$ 1s spectral regions of CPPA and CPHDA functionalized NRs (CPPA-NRs and CPHDA-NRs) are compared to pure CPHDA powders taken as reference. Both spectra of CPPA-NRs and CPHDA-NRs samples consist of two main components at $285.0 \mathrm{eV}\left(\mathrm{C}^{0}\right)$, due to aliphatic carbons, and at $288.9 \mathrm{eV}\left(\mathrm{C}^{3+}\right)$, due to the carboxylic group of CPPA and CPHDA. This assignment is also supported by the intensity ratio between $\mathrm{C}^{0}$ and $\mathrm{C}^{3+}$, which is $17 \pm 2$ for CPHDA-NRs and $3 \pm 1$ for CPPA-NRs. Taking into account a slight contribution to $\mathrm{C}^{0}$ component due to the adventitious carbon, these ratios are consistent with the values (15 and 2) expected from the molecular formulas. In addition, the $\mathrm{P} / \mathrm{C}_{\mathrm{C}^{3+}}$ atomic ratio for both CPHDA-NRs and CPPA-NRs calculated from $\mathrm{P} 2 \mathrm{p}$ band and from the $\mathrm{C}^{3+}$ component is close to 1 , according to the theoretical value. It is worth noting that the $\mathrm{BE}$ of the $\mathrm{C}^{3+}$ component for both grafted acids is shifted toward lower BE $(288.9 \mathrm{eV})$ compared to the BE value $(289.2 \mathrm{eV})$ of reference powders (Figure 5), thus suggesting that carboxylic moieties are deprotonated. Therefore, overall XPS results indicate that the surface grafting of bifunctional CPHDA and CPPA molecules leads to the deprotonation of both $\mathrm{POOH}$ and $\mathrm{COOH}$ moieties.

The same results have been achieved from the XPS characterization of rodlike powders functionalized with PPA, TDPA, CPHDA, and CPPA (see Supporting Information Table S1 and Figure S2), thus suggesting that phosphonic acids are similarly grafted on the $\mathrm{ZnO} \mathrm{NR}$ films and on the $\mathrm{ZnO}$ rodlike powders. This result is not unexpected since both films and powders are grown from the same precursor solution and possess similar rodlike structure and, likely, similar exposed surfaces.

FTIR Characterization. Further information about the grafting process on $\mathrm{ZnO}$ rods were provided by transmission FT-IR analysis of functionalized rodlike powders. In particular, the $\mathrm{C}-\mathrm{H}$ stretching region between 3000 and $2800 \mathrm{~cm}^{-1}$ and the region between 800 and $1800 \mathrm{~cm}^{-1}$, in which characteristic $\mathrm{P}=\mathrm{O}$ and $\mathrm{P}-\mathrm{O}$ stretching vibrations are present, have been reported in Figures 6 and 7, respectively. The $\mathrm{C}-\mathrm{H}$ stretching region of TDPA and CPHDA functionalized $\mathrm{ZnO}$ rods shows more intense $\mathrm{CH}_{2}$ asymmetric and symmetric stretching modes (at 2920 and $2850 \mathrm{~cm}^{-1}$ ) compared to PPA and CPPA functionalized rods due to the higher number of $\mathrm{CH}_{2}$ groups. In addition, both spectra of TDPA and PPA functionalized

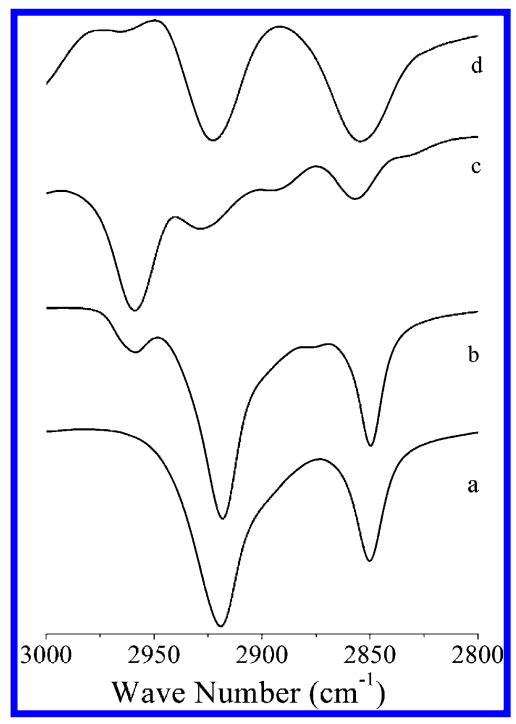

Figure 6. FT-IR spectra of $\mathrm{C}-\mathrm{H}$ stretching region of (a) CPHDA, (b) TDPA, (c) PPA, and (d) CPPA functionalized rodlike $\mathrm{ZnO}$ powders.

$\mathrm{ZnO}$ rodlike powders show intense bands due to $\mathrm{CH}_{3}$ asymmetric and symmetric stretches (2960 and $2900 \mathrm{~cm}^{-1}$ ) which, as expected, are not significantly present in the spectra of CPHDA and CPPA functionalized rods.

In the 900-1800 $\mathrm{cm}^{-1}$ region, FTIR spectra of all functionalized $\mathrm{ZnO}$ rods show significant changes compared to spectra of pure phosphonic acid powders (Figure 7). In particular, pure phosphonic acid powders show three characteristic peaks in the $900-1050 \mathrm{~cm}^{-1}$ range due to $\mathrm{P}-\mathrm{O}-\mathrm{H}$ group and a band at $1240 \mathrm{~cm}^{-1}$ related to $\mathrm{P}=\mathrm{O}$ stretching. ${ }^{55-57}$ This last band, in the case of PPA powders, is broadened and shifted in the $1240-1150 \mathrm{~cm}^{-1}$ range due to the formation of intermolecular $\mathrm{H}$ bonds. These bands are either not present or much lower in the spectra of the phosphonic acids anchored on $\mathrm{ZnO}$. A new strong band around $1040 \mathrm{~cm}^{-1}$ is instead observed. This band is typically assigned to the stretches of $\mathrm{PO}_{3}{ }^{2-}$ group anchored to the surface through a multidentate bonding ${ }^{55-57}$ which involves both $\mathrm{P}-\mathrm{O}$ and $\mathrm{P}=\mathrm{O}$ terminations (see DFT modeling in the following section).

The strong peak due to the $\mathrm{C}=\mathrm{O}$ stretch of the carboxylic group, which is typically present at $1730-1700 \mathrm{~cm}^{-1}$ in the spectra of CPHDA and CPPA powders (Figure 7), is absent in the spectra of $\mathrm{ZnO}$ rods functionalized with CPHDA and CPPA. Two new bands, at 1580 and $1410 \mathrm{~cm}^{-1}$, which are characteristic of the asymmetric $\nu_{\text {as }}\left(\mathrm{COO}^{-}\right)$and the symmetric $\nu_{\mathrm{s}}\left(\mathrm{COO}^{-}\right)$stretches of the carboxylate group, ${ }^{58,59}$ are instead present.

Spectra show that almost all $\mathrm{POOH}$ and $\mathrm{COOH}$ moieties are deprotonated, indicating a simultaneously interaction with the surface. These data can be consistent with a model in which molecules are bonded to the surface through the phosphonic group, but they bend to have also a simultaneous interaction with the surface through $\mathrm{COOH}$ moiety.

To demonstrate that the surface anchoring of carboxyalkylphosphonic molecules is mainly driven by the $\mathrm{POOH}$ moiety, a competitive anchoring experiment adopting an ethanol solution of BrHDA and TDPA (BrHDA/TDPA molar ratio 1:1) was performed on both $\mathrm{ZnO} \mathrm{NR}$ films and $\mathrm{ZnO}$ rodlike powders. A Br-marked carboxylic acids was chosen to easy evaluate the presence of the carboxylic acid through XPS. XPS spectra of both $\mathrm{ZnO}$ films and powders treated with the BrHDA/TDPA 


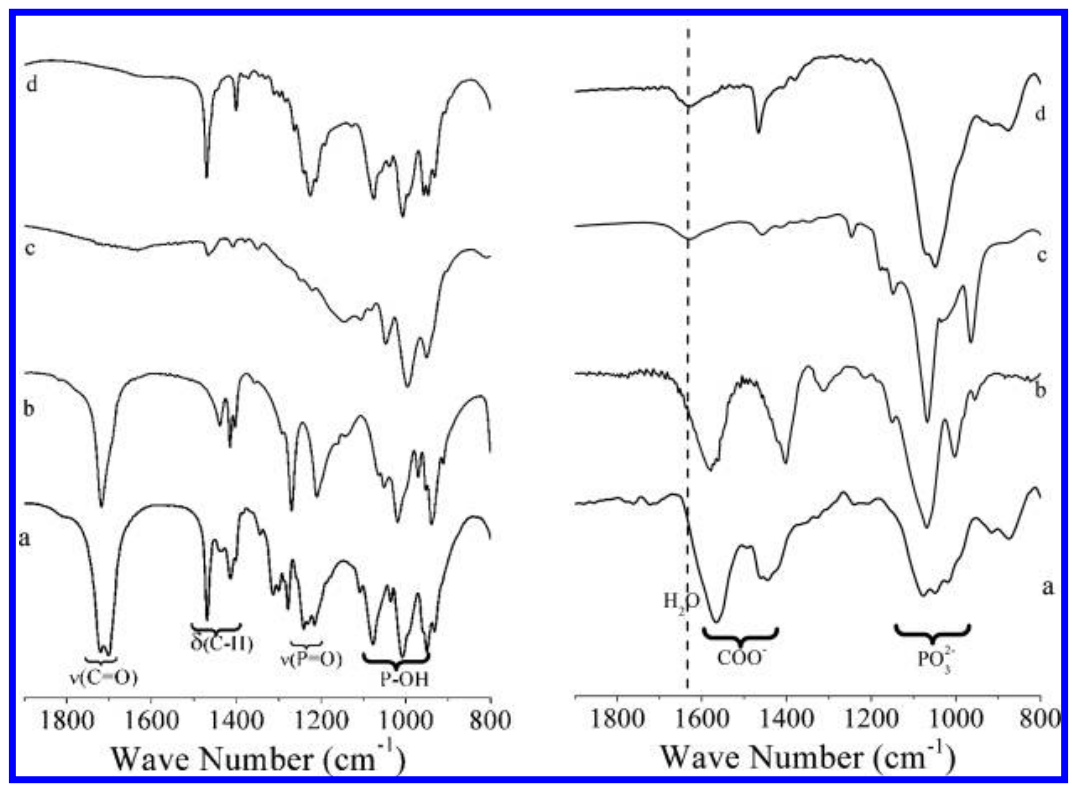

Figure 7. FT-IR spectra of (a) CPHDA, (b) CPPA, (c) PPA, and (d) TDPA as powder (left) and grafted on ZnO rodlike powders (right).

solution show P 2p signals at $133.2 \mathrm{eV}$ due to TDPA molecules, but no signals in the $\mathrm{Br} 3 \mathrm{~d}$ region (Figure 8 ), thus indicating that only TDPA molecules have been anchored on $\mathrm{ZnO}$.

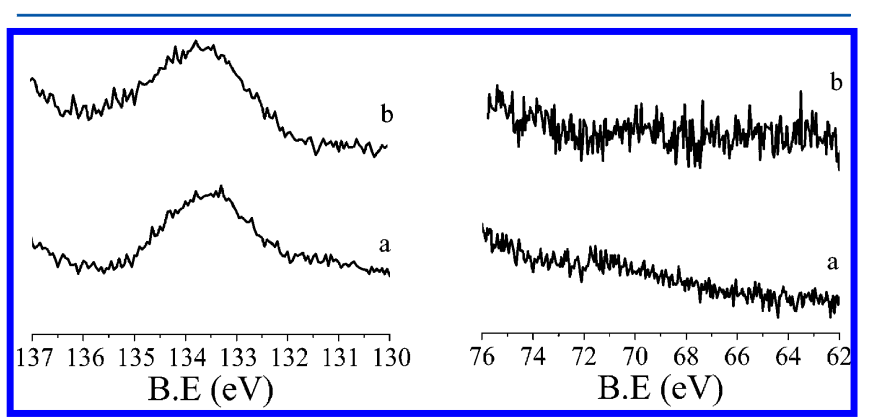

Figure 8. $\mathrm{P} 2 \mathrm{p}$ (left) and $\mathrm{Br} 3 \mathrm{~d}$ (right) XPS spectral regions of $\mathrm{ZnO}$ (a) powders and (b) films treated with BrHDA/TDPA solution for the competitive anchoring experiment.

This result has been confirmed by FTIR spectrum of $\mathrm{ZnO}$ powders exposed to BrHDA/TDPA mixture, since the broad band due to $\mathrm{P}-\mathrm{O}-\mathrm{Zn}$ stretches at $1040 \mathrm{~cm}^{-1}$ is present, while the signals associated with carboxylic/carboxylates groups are not detectable (Figure 9).

Overall results suggest that bifunctional carboxyalkylphosphonic acids bond through phosphonate groups, but a further interaction between the carboxylic moiety and suited surface $\mathrm{ZnO}$ sites is present.

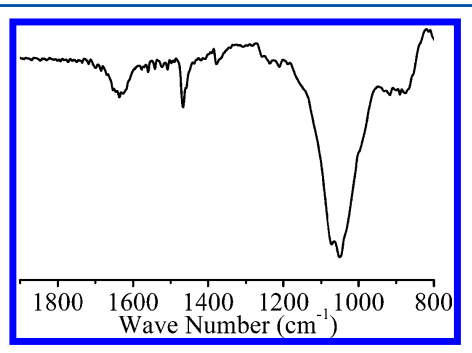

Figure 9. FTIR $1900-800 \mathrm{~cm}^{-1}$ spectral region of $\mathrm{ZnO}$ powders treated with the BrHDA/TDPA solution.
Note that this secondary interaction can be limited by increasing the surface density of anchored molecules. Two CPHDA functionalized rodlike powders were prepared adopting different concentrations ( 1 and $10 \mathrm{mM}$ ) of the CPHDA grafting solutions. The $\mathrm{P} / \mathrm{Zn}$ atomic ratio (and, hence, the CPHDA surface density) of functionalized powders, estimated from XPS, increases from 0.25 to 0.35 when CPHDA grafting solution concentration increases from 1 to $10 \mathrm{mM}$. FTIR spectra (Figure 10) show that, besides

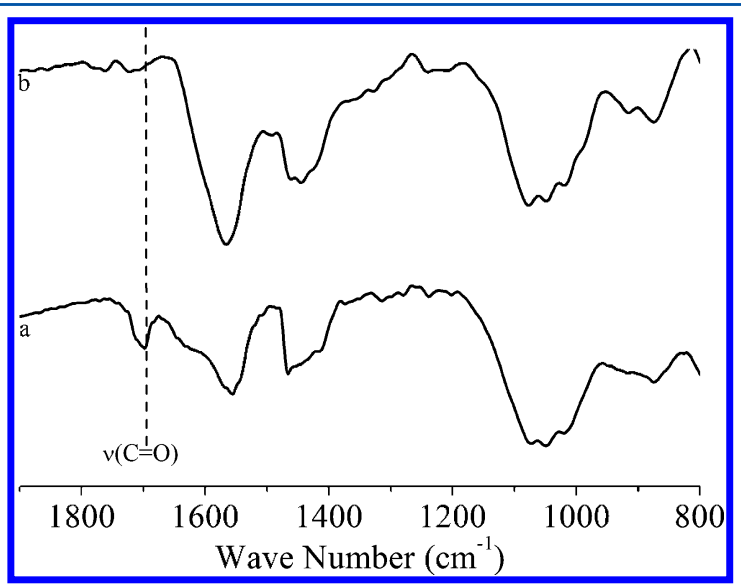

Figure 10. FT-IR spectra of $\mathrm{ZnO}$ powders after grafting reaction with CPHDA (a) $10 \mathrm{mM}$ and (b) $1 \mathrm{mM}$ solution.

carboxylate moieties $\left(\nu_{\mathrm{as}}\left(\mathrm{COO}^{-}\right)\right.$and $\nu_{\mathrm{s}}\left(\mathrm{COO}^{-}\right)$at 1580 and $\left.1410 \mathrm{~cm}^{-1}\right)$, not-deprotonated carboxylic terminations $(\nu(\mathrm{CO})$ at $1710 \mathrm{~cm}^{-1}$ ) are present in the sample obtained at high CPHDA concentration. By contrast, no peaks around 1710 $\mathrm{cm}^{-1}$ are observed in the spectrum of the other sample. This behavior is the result of the higher surface density of the phosphonic acid which limits the bending capability of anchored molecules and also reduces the amount of surface free sites available for the interaction with the $\mathrm{COOH}$ termination.

Adsorption Process: Theoretical Modeling. To better understand and clarify the above-discussed interactions 


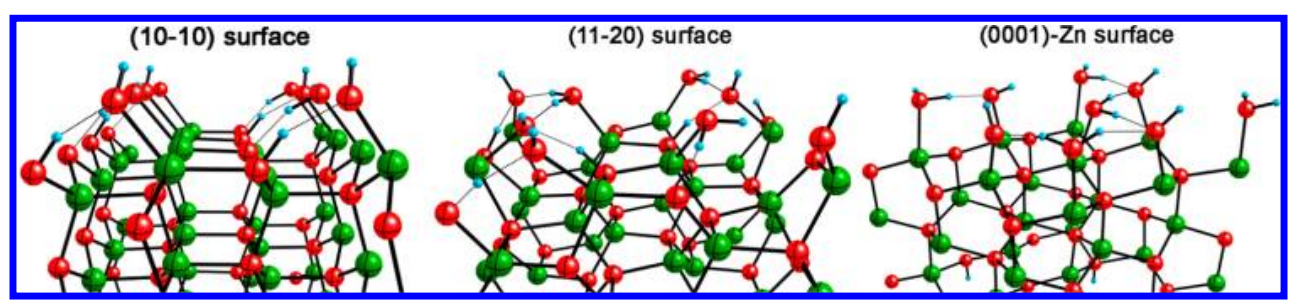

Figure 11. $\mathrm{ZnO}$ surfaces after water adsorption process and surface dissociations.

Scheme 1. Scheme of the Interaction of Bifunctional CPPA with $\mathrm{ZnO}$ Surfaces

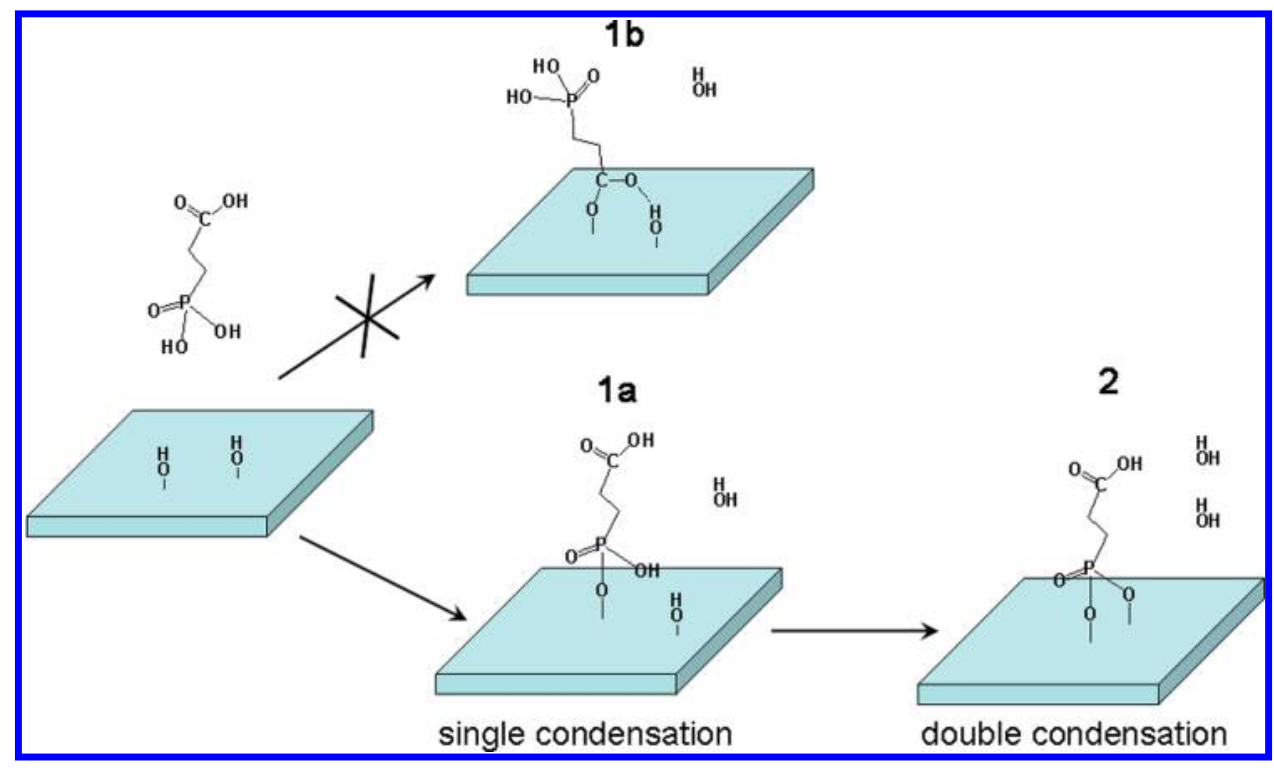

involved in the anchoring of bifunctional carboxyalkylphosphonic acids onto the $\mathrm{ZnO}$ surface, DFT modeling was performed. Theoretical model was performed on CPPA for which simultaneous $\mathrm{POOH}$ and $\mathrm{COOH}$ interactions with the surface are less expected, due to the shortness of the alkyl chain.

DFT calculations were performed to model CPPA anchoring on the hydroxylated (11-20), (10-10), and (0001)-Zn surfaces shown in Figure 11. Details on these surfaces are enclosed in the Supporting Information.

CPPA adsorption process was modeled approaching the CPPA molecule either with the phosphonic or the carboxylic group to the hydroxyl groups of the (10-10) surface to promote an acid/base condensation process. We have found that the condensation with the phosphonic acid (structure 1a in Scheme 1) is $12.5 \mathrm{kcal} / \mathrm{mol}$ more stable than the analogous condensation with the carboxylic group (structure $\mathbf{1 b}$ in Scheme 1). This result confirms that the interaction of CPPA through the phosphonic group is preferred over the interaction through the carboxylic group, in excellent agreement with experimental data. Once the CPPA is adsorbed by a single condensation, the phosphonic group can interact with the surface by means of a further condensation process. In this case, the interaction between CPPA and $\mathrm{ZnO}$ surface consists of a double condensation between the two $\mathrm{P}-\mathrm{O}-\mathrm{H}$ terminations and the surface hydroxyl groups on two $\mathrm{Zn}$ atoms, leading to a bridging bidentate coordination bonding (structure $\mathbf{2}$ in Scheme 1). Energetic $(\Delta G)$ of single and double condensation of the CPPA molecule has been compared in the case of (10$10),(11-20)$, and (0001) surfaces according to reaction 1 and eq 2 :

$$
\begin{aligned}
& \mathrm{ZnO} \cdot 2 \mathrm{H}_{2} \mathrm{O}_{\text {Surf }}+\mathrm{CPPA} \rightarrow \mathrm{ZnO} \cdot \cdot(2-n) \mathrm{H}_{2} \mathrm{O} \\
& . \cdot \mathrm{CPPA}_{\text {Surf }}+n \mathrm{H}_{2} \mathrm{O}
\end{aligned}
$$

where $\mathrm{ZnO} \cdot 2 \mathrm{H}_{2} \mathrm{O}_{\text {Surf }}$ is the hydroxylated $\mathrm{ZnO}$ surfaces and $\mathrm{ZnO} \cdot(2-n) \mathrm{H}_{2} \mathrm{O} \cdot \cdot \mathrm{CPPA}_{\text {Surf }}$ is the $\mathrm{ZnO}$ surface after the CPPA adsorption, $n=1$ for a single condensation and $n=2$ for a double condensation;

$$
\Delta G=\Delta H-T \Delta S+\Delta G_{\text {solv }}
$$

where $\Delta H$ can be approximated by the variation of the electronic energy in the reaction 1 as calculated after the optimization calculations, $T \Delta S$ is the entropic contribution, and $\Delta G_{\text {solv }}$ is the solvation effect when CPPA adsorb on the surface and the water is released into the solvent. In this case

$$
\Delta G_{\text {solv }}=n \Delta G_{\text {solv }}\left(\mathrm{H}_{2} \mathrm{O}\right)-\Delta G_{\text {solv }}(\mathrm{CPPA})
$$

$\Delta G_{\text {solv }}\left(\mathrm{H}_{2} \mathrm{O}\right)$ and $\Delta G_{\text {solv }}(\mathrm{CPPA})$ are the energy associated with the solvation of one water molecule and one CPPA molecule, respectively, in toluene. Solvent effects on the surfaces are neglected. Entropic and solvation effects cannot be neglected in the energetic comparison between mono and double condensation of the phosphonic group on the surface because of the inherent bimolecular process ( 1 particle $\rightarrow 2$ particles process). In all other calculations these energetic contributions have been considered similar and, hence, they have been neglected.

We have found that on all surfaces double condensation is preferred over the single condensation $(\Delta G=-15.9 \mathrm{kcal} / \mathrm{mol}$ for the double condensation vs $-15.2 \mathrm{kcal} / \mathrm{mol}$ for the single one on the (10-10) surface, $\Delta G=-27.4 \mathrm{kcal} / \mathrm{mol}$ for the 


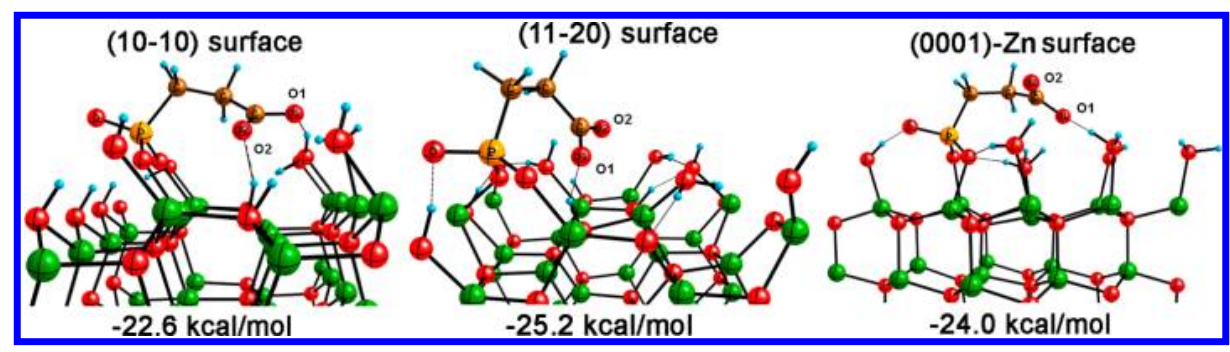

Figure 12. Computed structures of CPPA condensed on 11-20, 0001, and 10-10 $\mathrm{ZnO}$ surfaces. $\mathrm{O}$ atoms in red, $\mathrm{P}$ in orange, $\mathrm{C}$ in brown, $\mathrm{H}$ in light blue, and $\mathrm{Zn}$ in green.

double condensation vs $-17.2 \mathrm{kcal} / \mathrm{mol}$ for the single condensation on the (11-20) surface and $\Delta G=-35.2 \mathrm{kcal} /$ mol for the double condensation vs $-11.1 \mathrm{kcal} / \mathrm{mol}$ for the single one on the (0001) surface), mainly due to the entropic and solvation gains. Starting from the CPPA molecule anchored through a double condensation (structure 2) of the phosphonic group, we have checked the most stable configuration of the CPPA on each surface by testing different geometrical arrangements of the CPPA chain. In particular, we have bent the CPPA chain to promote eventual interactions between the carboxylic acid and the surface. Figure 12 shows the most stable structures derived from the interaction of CPPA with the investigated surfaces (see Supporting Information for the other configurations investigated). First of all we can observe on the (11-20) and (0001)-Zn surfaces a strong H-bonding interaction of the $\mathrm{P}=\mathrm{O}$ termination with a surface hydroxyl group, while on the (10-10) surface this interaction is not active (Table 2).

Table 2. Geometrical Parameters Involved in the $\mathrm{H}$ Bond Interactions between CPPA and $\mathrm{ZnO}$ Surfaces ${ }^{a}$

\begin{tabular}{llll} 
& $(10-10)$ surface & $(11-20)$ surface & \multicolumn{1}{c}{$\begin{array}{c}(0001)-\mathrm{Zn} \\
\text { surface }\end{array}$} \\
\hline stabilization energy & $-22.6 \mathrm{kcal} / \mathrm{mol}$ & $-25.2 \mathrm{kcal} / \mathrm{mol}$ & $-24.0 \mathrm{kcal} / \mathrm{mol}$ \\
(surf) $\mathrm{OH} \cdots \mathrm{O}=\mathrm{P}$ & & $1.57\left(167.2^{\circ}\right)$ & $1.55\left(166.1^{\circ}\right)$ \\
(surf) $\mathrm{OH} \cdots \mathrm{O} 1 \mathrm{C}$ & $1.58\left(156.8^{\circ}\right)$ & $1.54\left(149.1^{\circ}\right)$ & $1.56\left(161.4^{\circ}\right)$ \\
(surf) $\mathrm{OH} \cdots \mathrm{O} 2 \mathrm{C}$ & $1.55\left(158.1^{\circ}\right)$ & &
\end{tabular}

${ }^{a}$ In parentheses, the $\mathrm{O}-\mathrm{H} \cdots \mathrm{O}$ angle is reported. Distances are in angstroms and angles in degrees. Labels refer to Figure 12.

Approaching the carboxylic acid group of CPPA anchored molecules on the surface, an acid/base proton exchange is observed in all cases (Figure 12) leading to the formation of a carboxylate group, that, in turn, is involved in $\mathrm{H}$ bonds promoted by the $\mathrm{OH}$ surface terminations.

The $\mathrm{H}$ bonds between the $\mathrm{OH}$ surface groups and the CPPA carboxylate group are confirmed by the $\mathrm{H}$... O distances shown in Table 2. In particular, on (11-20) and (0001)-Zn surfaces only one $\mathrm{H}$ bond is observed, while on (10-10) surface both oxygen atoms of the carboxylate groups are involved in the $\mathrm{H}$ bonds promoted by the hydroxyl groups of the surface.

The (11-20) and (0001)-Zn surfaces show comparable stabilization energy $(-25.2$ and $-24.0 \mathrm{kcal} / \mathrm{mol}$, respectively). By contrast, the (10-10) surface is slightly less stabilized (-22.6 $\mathrm{kcal} / \mathrm{mol}$ ) The difference in the energy stabilization obtained on the (10-10) surface compared with the other two surfaces (11-20) and (0001) is mainly due to the different $\mathrm{H}$ bonding between surface and CPPA molecule (one $\mathrm{H}$ bond with $\mathrm{P}=\mathrm{O}$ and with $\mathrm{C}-\mathrm{O}$ on the (11-20) and (0001)-Zn surfaces and two $\mathrm{H}$ bonds with $\mathrm{C}-\mathrm{O}$ on the (10-10) surface; see Table 2).
Vibrational analysis on CPPA molecule in the gas phase and chemisorbed on the surface was performed to understand the influence of the surface interaction on the IR signals. In particular, we followed the $\mathrm{P}=\mathrm{O}$ and the $\mathrm{C}=\mathrm{O}$ stretch shifts in the main representative structures (Figure 12).

On the (11-20) and (0001) surfaces, the $\mathrm{P}=\mathrm{O}$ stretching frequency passes from $1277 \mathrm{~cm}^{-1}$ (noninteracting molecule) to $1060 \mathrm{~cm}^{-1}$ in the adsorbate species mixing its vibrational modes with the other $\mathrm{P}-\mathrm{O}$ single bonds. This shift is mainly due to the $\mathrm{H}$ bonding between the $\mathrm{P}=\mathrm{O}$ group and the surface hydroxyl group. By contrast, the analogous shift is reduced on the $(10-10)$ surface $\left(\mathrm{P}=\mathrm{O}\right.$ stretching centered at $\left.1229 \mathrm{~cm}^{-1}\right)$ where the $\mathrm{H}$ bond is not active.

On the other hand, the $\mathrm{C}=\mathrm{O}$ stretching frequency starts from $1769 \mathrm{~cm}^{-1}$ in the noninteracting configuration and splits in two components centered at 1550 and $1350 \mathrm{~cm}^{-1}$ in the adsorbate species. These components are associated with the asymmetric and symmetric $\mathrm{COO}^{-}$stretching modes, respectively. These theoretical results agree well with the trend experimentally observed. From the comparison between theoretical and experimental results, it is possible to understand how the phosphonic acid interacts with the surface. In particular, chemisorption of the phosphonic acid on $\mathrm{ZnO}$ occurs preferentially via a double condensation of $\mathrm{P}-\mathrm{O}-\mathrm{H}$ terminations. In addition, the carboxylic group of the chemisorbed molecule exchanges the acid proton with the surface, and the resulting carboxylate remains close to the surface through $\mathrm{H}$ bondings. Finally, the $\mathrm{P}=\mathrm{O}$ group is involved (where it is possible) in an $\mathrm{H}$ bond promoted by the hydroxyl groups of the surface.

The preferred surface configurations of CPPA molecules as a function of the CPPA concentration was computed by putting onto the $\mathrm{ZnO}(10-10)$ surface $1,2,3$, and 4 CPPA molecules corresponding to a surface coverage of $0.25,0.50,0.75$, and 1.0 monolayer (Figure 13).

The increase of the surface concentration changes the configuration of the anchored molecules by removing the carboxylic acid interaction with the surface. At 0.5 monolayer coverage, all the surface sites are engaged by interaction with both the phosphonic and carboxylate groups. At 0.75 monolayer coverage, the interaction with a further CPPA molecule requires the removing of the carboxylic group from the surface and the vertical arrangement of two CPPA molecules (Figure 13). At this stage, $\mathrm{H}$ bond interactions among the carboxylic groups of the vertical arranged CPPA molecules are present as indicated by the $\mathrm{O} \cdots \mathrm{H}$ distance $(2.1$ $\AA)$ and the $\mathrm{O} \cdots \mathrm{H}-\mathrm{O}$ angle $\left(160^{\circ}\right)$. At 1.0 monolayer coverage all the molecules have a vertical arrangement with respect to the surface, and the carboxylic acid terminations interact with each other through $\mathrm{H}$ bonds. 


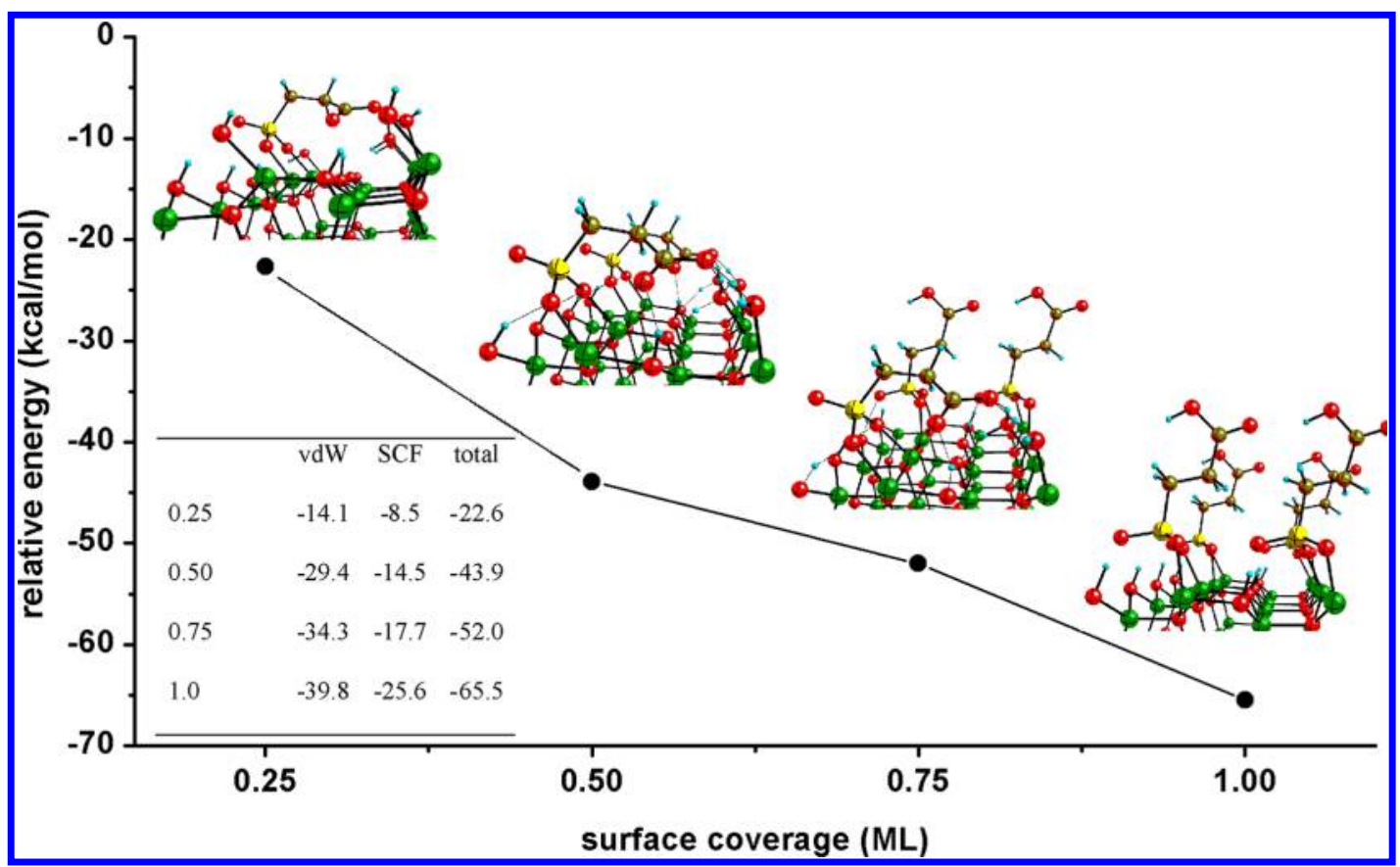

Figure 13. Energy trend along CPPA surface coverage. The energy contributions (kcal/mol) along the CPPA coverage pathway on the (10-10) surface are shown in the inset.

Van der Waals (vdW) contributions have been evaluated to understand the role of dispersive forces in the CPPA monolayer formation. It was found that vdW contribution is about $14 \mathrm{kcal} /$ mol for the adsorption of the first and the second ( 0.25 and 0.50 of coverage, respectively) CPPA molecule, while for the adsorption of the other two CPPA molecules ( 0.75 and 1.0 of coverage) vdW contribution is reduced to about $5 \mathrm{kcal} / \mathrm{mol}$ (Figure 13, inset). These values indicate a more efficient dispersive interaction between the adsorbed CPPA molecule and the $\mathrm{ZnO}$ surface compared to the dispersive interaction among the adsorbed CPPA molecules. Note that DFT modeling of the concentration effects well agree with experimental results which showed the presence of the free carboxylic group (IR band at $1710 \mathrm{~cm}^{-1}$ ) in $\mathrm{ZnO}$-functionalized powders adopting concentrated carboxyalkylphosphonic acid solution.

\section{CONCLUSION}

In this study, spectroscopic (FTIR and XPS) characterization and DFT modeling have been combined to explain and understand the interactions which drive the surface anchoring of phosphonic acids on $\mathrm{ZnO}$ surface. Surface anchoring of monofunctional (PPA and TDPA) and bifunctional (CPPA and CPHDA) phosphonic acids occurs mainly through a multidentate bonding which involves both $\mathrm{P}=\mathrm{O}$ and $\mathrm{P}-\mathrm{O}$ terminations. For bifunctional acids, both $\mathrm{POOH}$ and $\mathrm{COOH}$ terminations interact simultaneously with the surfaces. DFT calculations have shown that the condensation with the phosphonic acid is more stable than the condensation with the carboxylic group in excellent agreement with experimental data. For these acids, the surface layer consists of a bended arrangement of molecules anchored through phosphonic groups and having a simultaneous acid/basic exchange between $\mathrm{COOH}$ and surface hydroxyls groups. Combined FTIR and DFT results indicate that this secondary interaction can be limited by increasing the surface density of anchored molecules.
DFT vibrational analysis performed on the main cleavage $\mathrm{ZnO}$ surfaces also allowed to model experimental FTIR spectra on the basis of the proposed surface arrangements of molecules. In particular, the observed shifts of the $\mathrm{P}=\mathrm{O}$ and $\mathrm{P}-\mathrm{O}$ stretches after surface anchoring have been modeled by DFT through a multidentate bonding involving the formation of two $\mathrm{P}-\mathrm{O}-\mathrm{Zn}$ bonds and a strong $\mathrm{P}=\mathrm{O}-\mathrm{-H}$ linkage between the phosphonic head and the surface.

\section{ASSOCIATED CONTENT}

\section{Supporting Information}

$\mathrm{XRD}$ patterns of synthesized $\mathrm{ZnO}$ films and powders (Figure $\mathrm{S} 1$ ); XPS analysis of functionalized $\mathrm{ZnO}$ powders and of reference phosphonic acids (Table S1 and Figure S2); further details on the theoretical model regarding the optimization of not-functionalized $\mathrm{ZnO}$ surface and less stable CPPA adsorption configurations (Figures S3-S7 and Tables S2 and S3). This material is available free of charge via the Internet at http://pubs.acs.org.

\section{AUTHOR INFORMATION}

\section{Corresponding Author}

*E-mail guido.condorelli@unict.it; Fax ++39 095580138; Ph + +390957385069.

\section{Notes}

The authors declare no competing financial interest.

\section{ACKNOWLEDGMENTS}

The authors thank CINECA (grant HP10BD82EA) for the availability of high performance computing resources and support and Ministero dell'Istruzione, dell'Università e della Ricerca (MIUR) for financial support through FIRB "ITALNANONET" (RBPR05JH2P) and "RINAME Rete Integrata per la NAnoMEdicina” (RBAP114AMK). 


\section{REFERENCES}

(1) Ulman, A. Chem. Rev. 1996, 96, 1533-1554.

(2) Hotchkiss, P. J.; Jones, S. C.; Paniagua, S. A.; Sharma, A.; Kippelen, B.; Armstrong, N. R.; Marder, S. R. Acc. Chem. Res. 2012, 45, 337-347.

(3) Wang, X.; Landis, E. C.; Franking, R.; Hamers, R. J. Acc. Chem. Res. 2010, 43, 1205-1215.

(4) DeRose, J. A.; Hoque, E.; Bhushan, B.; Mathieu, H. J. Surf. Sci. 2008, 602, 1360-1367.

(5) Hoque, E.; DeRose, J. A.; Kulik, G.; Hoffmann, P.; Mathieu, H. J.; Bhushan, B. J. Phys. Chem. B 2006, 110, 10855-10861.

(6) Ishizaki, T.; Okido, M.; Masuda, Y.; Naobumi, S.; Sakamoto, M. Langmuir 2011, 27, 6009-6017.

(7) Novak, M.; Ebel, A.; Meyer-Friedrichsen, T.; Jedaa, A.; Vieweg, B. F.; Yang, G.; Voitchovsky, K.; Stellacci, F.; Spiecker, E.; Hirsch, A.; Halik, M. Nano Lett. 2011, 11, 156-159.

(8) Acton, O.; Ting, G. G.; Shamberger, P. J.; Ohuchi, F. S.; Ma, H.; Jen, A. K.-J. ACS Appl. Mater. Interfaces 2010, 2, 511-520.

(9) Stern, E.; Klemic, J. F.; Routenberg, D. A.; Wyrembak, P. N.; Turner-Evans, D. B.; Hamilton, A. D.; LaVan, D. A.; Fahmy, T. M.; Reed, M. A. Nature 2007, 445, 519.

(10) Taratula, O.; Galoppini, E.; Mendelsohn, R. Langmuir 2009, 25, 2107-2113.

(11) Gulino, A.; Gupta, T.; Mineo, P. G.; Van der Boom, M. E. Chem. Commun. 2007, 46, 4878-4880.

(12) Gulino, A.; Gupta, T.; Altman, M.; Lo Schiavo, S.; Mineo, P. G.; Fragalà, I. L.; Evmenenko, G.; Dutta, P.; Van der Boom, M. E. Chem. Commun. 2008, 25, 2900-2902.

(13) (a) Liu, W. K.; Salley, M. G.; Gamelin, D. R. J. Phys. Chem. B 2005, 109, 14486-14495. (b) Levy-Clement, C.; Tena-Zaera, R.; Ryan, M. A.; Katty, A.; Hodes, G. Adv. Mater. 2005, 17, 1512-1515.

(14) Queffélec, C.; Petit, M.; Janvier, P.; Knight, D. A.; Bujoli, B. Chem. Rev. 2012, 112, 3777-3807.

(15) Shafi, K. V. P. M.; Ulman, A.; Yan, X.; Yang, N.-L.; Estournès, C.; White, H.; Rafailovich, M. Langmuir 2001, 17, 5093-5097.

(16) Pawsey, S.; Yach, K.; Reven, L. Langmuir 2002, 18, 5205-5212.

(17) Silverman, B. M.; Wieghaus, K. A.; Schwartz, J. Langmuir 2005, $21,225-228$.

(18) Wu, J.; Xue, D. Sci. Adv. Mater 2011, 3, 127-149.

(19) Hagen, J. A.; Kim, S. N.; Bayraktaroglu, B.; Leedy, K.; Chávez, J. L.; Loughnane, N. K.; Naik, R. R.; Stone, M- O. Sensors 2011, 11, 6645-6655.

(20) Pearton, S. J.; Chang, C. Y.; Chu, B. H.; Lo, C.-F.; Ren, F.; Chen, W.; Guo, J. IEEE J. Sel. Top. Quantum Electron. 2011, 17, 10921099.

(21) Ju, S.; Lee, K.; Janes, D. B.; Yoon, M.-Y.; Facchetti, A.; Marks, T. J. Nano Lett. 2005, 11, 2281-2286.

(22) Zhao, Q.; Xie, T.; Peng, L.; Lin, Y.; Wang, P.; Peng, L.; Wang, D. J. Phys. Chem. C 2007, 45, 17136-17145.

(23) Chung, J.; Myoung, J.; Oh, J.; Lim, S. J. Phys. Chem. C 2010, 49, 21360-21365.

(24) Gnichwitz, J.-F.; Marczak, R.; Werner, F.; Lang, N.; Jux, N.; Guldi, D. M.; Peukert, W.; Hirsch, A. J. Am. Chem. Soc. 2010, 132, 17910-17920

(25) Zhang, B.; Kong, T.; Xu, W.; Su, R.; Gao, Y.; Cheng, Y. Langmuir 2010, 26, 4514-4522.

(26) Voigt, M.; Klaum€unzer, M.; Ebel, A.; Werner, F.; Yang, G.; Marczak, R.; Spiecker, E.; Guldi, D. M.; Hirsch, A.; Peukert. J. Phys. Chem. C 2011, 115, 5561-5565.

(27) Kalblein, D.; Weitz, R. T.; Bottcher, H. J.; Ante, F.; Zschieschang, U.; Kern, K.; Klauk, H. Nano Lett. 2011, 11, 53095315.

(28) Taratula, O.; Galoppini, E.; Wang, D.; Chu, D.; Zhang, Z.; Chen, H. H.; Saraf, G.; Lu, Y. C. J. Phys. Chem. B 2006, 110, 6506.

(29) Sadik, P. W.; Pearton, S. J.; Norton, D. P.; Lambers, E.; Ren, F. J. Appl. Phys. 2007, 101, 104514.

(30) Chen, J.; Ruther, R. E.; Tan, Y.; Bishop, L. M.; Hamers, R. J. Langmuir 2012, 28, 10437-10445.
(31) Hotchkiss, P. J.; Malicki, M.; Giordano, A. J.; Armstrong, N. R.; Marder, S. R. J. Mater. Chem. 2011, 21, 3107-3112.

(32) Perkins, C., L. J. Phys. Chem. C 2009, 113, 18276-18286.

(33) Di Valentin, C.; Costa, D. J. Phys. Chem. C 2012, 116, 28192828.

(34) Le Bahers, T.; Pauporte, T.; Labat, F.; Lefevre, G.; Ciofini, I. Langmuir 2011, 27, 3442-3450.

(35) Fragalà, M. E.; Aleeva, Y.; Malandrino, G. Thin Solid Films 2011, 519, 7694-7701.

(36) Swift, I. L. Surf. Interface Anal. 1982, 4, 47-51.

(37) Briggs, D.; Beamson. G. Anal. Chem. 1992, 64, 1729-1736.

(38) The CP2K developers group, http://cp2k.berlios.de/.

(39) Goedecker, S.; Teter, M.; Hutter, J. J. Phys. Rev. B 1996, 54, 1703.

(40) Perdew, J. P.; Burke, K.; Ernzerhof, M. Phys. Rev. Lett. 1997, 78, 1396 (E).

(41) Grimme, S. J.; Antony, J.; Ehrlich, S.; Krieg, H. Comput. Chem. 2010, 132, 154104

(42) Tudisco, C.; Betti, P.; Motta, A.; Pinalli, R.; Bombaci, L.; Dalcanale, E.; Condorelli, G. G. Langmuir 2012, 28, 1782-1789.

(43) VandeVondele, J.; Hutter, J. J. Chem. Phys. 2007, 127, 114105.

(44) Meyer, B.; Marx, D. Phys. Rev. B 2003, 67, 035403.

(45) Diebold, U.; Koplitz, L. V.; Dulub, O. Appl. Surf. Sci. 2004, 237, $336-342$.

(46) Gaussian 09, Revision A.1: Frisch, M. J.; et al. Gaussian, Inc.: Pittsburgh, PA, 2009.

(47) (a) Hehre, W. J.; Ditchfield, R.; Pople, J. A. J. Chem. Phys. 1972, 56, 2257-2261. (b) Francl, M. M.; Pietro, W. J.; Hehre, W. J.; Binkley, J. S.; Gordon, M. S.; DeFrees, D. J.; Pople, J. A. J. Chem. Phys. 1982, 77, 3654-3665.

(48) (a) Miertus, S.; Tomasi, J. Chem. Phys. 1982, 65, 239-245. (b) Miertus, S.; Scrocco, E.; Tomasi, J. Chem. Phys. 1981, 55, 117129. (c) Cossi, M.; Barone, V.; Cammi, R.; Tomasi, J. Chem. Phys. Lett. 1996, 255, 327-335. (d) Cances, M. T.; Mennucci, V.; Tomasi, J. J. Chem. Phys. 1997, 107, 3032-3041. (e) Barone, V.; Cossi, M.; Tomasi, J. J. Comput. Chem. 1998, 19, 404-417.

(49) Keszthelyi, T.; Pàszti, Z.; Rigò, T.; Hakkel, O.; Telegdi, J.; Guczi, L. J. Phys. Chem. B 2006, 110, 8701-8714.

(50) Wagner, C. D.; Naumkin, A. V.; Kraut-Vass, A.; Allison, J. W.; Powell, C. J.; Rumble, Jr., J. R. NIST X-ray Photoelectron Spectroscopy Database, Version 3.4; National Institute of Standards and Technology: Gaithersburg, MD, 2003; http://srdata.nist.gov/xps/.

(51) Gawalt, E. S.; Lu, G.; Bernasek, S. L.; Schwartz, J. Langmuir 1999, 15, 8929-8933.

(52) Textor, M.; Ruiz, L.; Hofer, R.; Rossi, A.; Feldman, K.; Hahner, G.; Spencer, N. D. Langmuir 2000, 16, 3257-3271.

(53) Chen, Y.; Liu, W.; Ye, C.; Yu, L.; Qi, S. Mater. Res. Bull. 2001, $36,2605-2612$

(54) Tudisco, C.; Oliveri, V.; Cantarella, M.; Vecchio, G.; Condorelli, G. G. Eur. J. Inorg. Chem. 2012, DOI: 10.1002/ejic.201200510.

(55) Zhang, B.; Kong, T.; Xu, W.; Su, R.; Gao, Y.; Cheng, G. Langmuir 2010, 26, 4514-4522.

(56) Dembereldorj, U.; Ganbold, E.-O.; Seo, J.-H.; Lee, S. Y.; Ik Yang, S.; Joo, S.-W. Vib. Spectrosc. 2012, 59, 23-28.

(57) Luschtinetz, R.; Seifert, G.; Jaehne, E.; Adler, H.-J. P. Macromol. Symp. 2007, 254, 248-253.

(58) Zhang, L.; He, R; Gu, H.-C. Appl. Surf. Sci. 2006, 253, 26112617.

(59) Nakamoto, K. Infrared and Raman Spectra of Inorganic and Coordination Compounds; Wiley: New York, 1986. 